\title{
The thermal decomposition of furfural: molecular chemistry unraveled
}

Florence H. Vermeire ${ }^{\mathrm{a}}$, Hans-Heinrich Carstensen ${ }^{\mathrm{a}}$, Olivier Herbinet ${ }^{\mathrm{b}}$, Frédérique Battin-Leclerc ${ }^{\mathrm{b}}$, Guy B. Marin ${ }^{\mathrm{a}}$, Kevin M. Van Geemª

${ }^{a}$ Laboratory for Chemical Technology, Ghent University, Technologiepark 914, 9052 Gent, Belgium

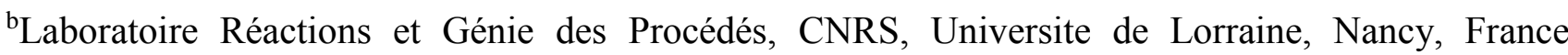
*Corresponding author: Technologiepark 914, 9052 Gent, Belgium, fax: +32 92645824, e-mail: kevin.vangeem@ugent.be

Colloquium: Gas-phase kinetics

\section{Wordcount method 1:}

Abstract : 230 words

Total: 5559 words $(\max =5800$ words $)$

Text (incl. intro, body, concl, ackn): 4066-figure captions $(24+23+37+15)=3967$ words

Figure 1: $144 \times 105.6=508.6+24($ caption $)=532.6$ words

Figure $2: 144 \times 68.9=347.2+23($ caption $)=370.2$ words

Figure 3: $67 \times 30.4=88.9+37$ (caption) $=125.9$ words

Figure $4: 67 \times 13.5=51.7+22($ caption $)=73.7$ words

References: $(26+2)$ x 2.3 x $7.6=489.4$ words

Supporting information: experimental data (see attached) 


\begin{abstract}
The thermal decomposition of furfural is investigated experimentally and through theoretical calculations at the CBS-QB3 level of theory. Furfural is a major product observed during biomass pyrolysis, but despite its importance there are many speculations about the thermal decomposition channels of this compound. To address these open questions new experiments are performed in a jetstirred reactor at atmospheric pressure and temperatures ranging from $900-1100 \mathrm{~K}$ with a furfural inlet mole fraction of 0.005 and He as diluent. The residence time is set to $2 \mathrm{~s}$. The main products observed by $\mathrm{GC}$ analysis are $\mathrm{CO}, \mathrm{CO}_{2}, \alpha$-pyrone, furan, 3-furaldehyde, propyne, propadiene, acetylene, methane and benzene. Small amounts of other aromatics, e.g. toluene, styrene, benzaldehyde and phenol are observed as well.
\end{abstract}

Theoretical calculations at the CBS-QB3 level are used to extend the furfural potential energy surface and to identify possible reaction pathways to the observed products. The unimolecular non-radical decomposition channel through $\alpha$-pyrone as proposed in literature is confirmed as the main channel, but carbene pathways are found to make small contributions as well. Furthermore, pericyclic reactions are suggested to contribute to the molecular elimination of $\mathrm{CO}$ in open-chain molecules and Diels Alder reactions are found to be important for the formation of $\mathrm{CO}_{2}$ and aromatics. Finally, even radical chemistry initiated by homolytic scission of the approximately $380 \mathrm{~kJ} / \mathrm{mol}$ strong $\mathrm{C}-\mathrm{H}$ bond in the furfural carbonyl group has a non-negligible influence.

\title{
Keywords
}

Furfural, pyrolysis, jet-stirred reactor, carbene, Diels Alder 


\section{Introduction}

The utilization of renewable resources such as lignocellulosic biomass to address the need for transportation fuels and chemicals is an ongoing topic of research. The thermochemical conversion of biomass yields non-condensable gases, a liquid fraction and solid material. The liquid fraction, also known as bio-oil, contains a wide variety of organic molecules that have promising fuel properties or can serve as platform molecules in chemical industry [1]. Furfural (2-furaldehyde), an aromatic aldehyde, has not only been identified as one of the major compounds produced during the pyrolysis of biomass [2-6] but also as a versatile base chemical for fuels and fine chemical production [2, 7]. The US Department of Energy listed furfural as one of the top bio based products from bio refinery carbohydrates [8]. Despite of its importance in the biomass conversion process, little is known about the thermal decomposition chemistry of furfural. Such knowledge is important to predict, for example, how furfural residuals found in bio refinery oil react in steam-cracking applications.

To the best of our knowledge, only four experimental studies on furfural pyrolysis are available in the open literature. Many years ago, in 1932, Hurd and Goldsby [9] used a quartz tube reactor to explore the direct production of furan from furfural pyrolysis. Various temperatures and space times were explored. Next to furan, large amounts of gases were detected with $\mathrm{CO}$ as the major product. Grela et al. $[10,11]$ investigated furfural pyrolysis in a flow reactor at low pressures by either modulated beam mass spectrometry [10] or IR analysis [11]. Vinylketene is proposed as major initial product and the contribution of radical chemistry is ruled out. Vasiliou et al. [12] performed experiments of furfural thermal decomposition in a micro tubular flow reactor at low pressures. Species profiles were detected by matrix IR spectroscopic and photo-ionization molecular beam mass spectrometry. Although these authors could not rule out the presence of vinylketene, they argue based on observed product ratios that furan is the main contributor to the $\mathrm{m} / \mathrm{z} 68$ ion signal. IR spectra did not provide conclusive additional information as all known vinylketene bands suffer from overlaps by other species. Wu et al. 
[13] studied pyrolysis products of furan and some derivatives in Py-GC-MS at $1100^{\circ} \mathrm{C}$, however with the focus on the formation of polycyclic aromatic hydrocarbons (PAH).

Different reaction pathways have been proposed in literature to be important in the thermal decomposition of furfural. First, a 1,2-shift of the carbonyl hydrogen atom to the $\alpha$-position of the furan ring in furfural can directly form furan and CO. This pathway does however not allow the formation of vinylketene. Therefore, Grela et al. [14] proposed the involvement of a ring opening, similar to pathways suggested for furan decomposition. Based on analogy to furan, a carbene mechanism as reported by Sendt et al. [15] is also possible as discussed shortly by Vasiliou et al. [12]. Latter group found however a lower unimolecular ring-opening pathway that does not involve carbenic intermediates. It is a concerted reaction in which the carbonyl hydrogen atom migrates to the furan ring which simultaneously ring-opens to produce the cis isomer of formylvinylketene (cis- $\mathrm{O}=\mathrm{C}=\mathrm{CH}-$ $\mathrm{CH}=\mathrm{CH}-\mathrm{CH}=\mathrm{O}$ ). Latter isomerizes through a low barrier to $\alpha$-pyrone or dissociates through a higher barrier to furan and CO. This mechanism would predict the formation of large amounts of $\alpha$-pyrone, which has not yet been detected experimentally as a major intermediate in furfural pyrolysis. In principle, radical chemistry could also play a role, but Grela et al. [11] as well as Vasiliou et al. [12] concluded based on their experimental evidence that radical reactions are not important at their respective conditions. However, contribution of radical reactions might be important at different reacting conditions. The difference in barrier heights between the molecular pathway and the formation of radicals through homolytic bond scissions is only $90 \mathrm{~kJ} / \mathrm{mol}$.

The purpose of this work is twofold. First, the initial products formed during furfural pyrolysis are investigated experimentally in a jet-stirred reactor with online species detection by GC, which allows the identification of isomers of furfural and thus the verification of the pathway proposed by Vasiliou et al. [12]. In contrast to previous experiments, the measurements are performed at atmospheric pressure. Secondly, the contribution of various channels for furfural decomposition, proposed in 
literature, are investigated theoretically and the PES for furfural is extended. The different channels that are believed to contribute to the thermal decomposition of furfural are discussed in detail.

\section{Experimental methods}

The experimental set-up has been described in detail elsewhere by Herbinet et al. [16]. The main features of the apparatus and analytical equipment are given below.

Furfural (Sigma-Aldrich, 99\%) is fed to an evaporator kept at $443 \mathrm{~K}$ and mixed with Helium (Messer, 99.99\%). Oxygen (Messer, 99.999\%) is added to the flow for oxidation experiments. The gaseous flow rates are controlled with Bronkhorst IN-FLOW controllers and the liquid furfural mass flow rate is regulated bya Bronkhorst M12 Coriolis flow controller. The mole fraction of furfural is set to 0.005 for all experimental conditions.

The gaseous mixture is fed to the isothermal quartz reactor through an annular preheating zone. The first part of the preheating zone is kept at $473 \mathrm{~K}$ and the temperature of the second part is set to the same temperature as the reactor. The four nozzles at the inlet of the reactor are designed to limit temperature and concentration gradients inside the reactor. Heating of the preheating zone and the reactor is done with Thermocoax resistance wires and a type $\mathrm{K}$ thermocouple measures the temperature at the center of the reactor. The pressure is set with a needle valve downstream of the reactor. The reactor has a fixed volume of $81.2 \mathrm{~cm}^{3}$ and the pressure equals 1.07 bar for all experiments. The temperature ranges from $800-1100 \mathrm{~K}$. The residence time, calculated with a fixed inlet flow rate of $41.9 \mathrm{~cm}^{3} \mathrm{~s}^{-1}$ and the reactor temperature and pressure, equals $2 \mathrm{~s}$.

The products are quantified online with 3 different gas chromatographs (GC). The outlet of the quartz reactor is connected with the GC's through heated $(433 \mathrm{~K})$ transfer lines to avoid condensation. The first GC is equipped with a Carbosphere column, a thermal conductivity detector and argon as carrier gas. $\mathrm{CO}, \mathrm{CO}_{2}$ and $\mathrm{CH}_{4}$ mole fractions can be determined with this $\mathrm{GC}$. The other GC's have a PLOTQ capillary column and a flame ionization detector (FID) preceded by a methanizer or a HP-5ms capillary column and a FID. A separate GC, with either a PLOT-Q or HP-5ms column, connected to a 
quadrupole mass spectrometer is used for offline product identification. For this analysis, the reactor effluent is trapped with the use of liquid nitrogen, dissolved in acetone and injected into the GC column.

Product mole fractions are calibrated by either injecting a known amount of the species in the GC or with the effective carbon number method. If the first method is used, the relative experimental error equals $5 \%$ based on experience. If calibration is done with the effective carbon number method, the relative experimental error is assumed to be $10 \%$. The carbon balances are closed within 5\% at most conditions. The configuration of the analysis section used during experiments does not allow the quantification of hydrogen gas. Water cannot be detected with this setup, hence the hydrogen and oxygen elemental balances are not available.

\section{Computational method}

Some pathways are proposed to the main thermal decomposition and oxidation products of furfural. To support these pathways, quantum mechanical calculations have been carried out with the highperformance supercomputer at Ghent University at the CBS-QB3 level of theory [17] as implemented in Gaussian 09 [18]. The results of the electronic structure calculations are used to calculate the heat capacities at different temperatures, the standard entropy and the standard enthalpy of formation. Most internal modes are treated as harmonic oscillators. The modes that resemble rotations around a single bond in both stable species and transition states are treated as 1-dimensional internal rotors, as long as the rotational barrier does not exceed $40 \mathrm{~kJ} \mathrm{~mol}^{-1}$. The hindrance potentials are calculated at the B3LYP/6-31G(d) level of theory with relaxed surface scans in which all coordinates, except for the dihedral angle of interest, are re-optimized at each scan angle. The Fourier series expression of the hindrance potential together with reduced moment of inertia calculated at the $\mathrm{I}^{(2,3)}$ level, as defined by East and Radom [19], are used to construct the Schrödinger equation for 1-dimensional internal rotation. The eigenvalues of the solution are used to determine the partition function as a function of temperature. The thermodynamic data is calculated from the total partition function after correction 
for the symmetry and the number of optical isomers. For the calculation of the enthalpy of formation, the atomization method is applied. The enthalpy of formation calculated at the CBSQB3 level of theory is corrected with spin-orbit corrections [20] and empirically with bond additive corrections (BAC) [21] for usage in the model. As BACs are not defined for transition states, the enthalpy of formation used in the potential energy surface is not corrected.

\section{Results}

\subsection{Furfural pyrolysis data in a jet-stirred reactor}

The experimentally obtained mole fractions of furfural and the main decomposition products are presented in Figure 1. Experimental mole fractions of all species are provided in the supporting information. The conversion of furfural starts at $900 \mathrm{~K}$. $\alpha$-pyrone is observed as one of the first products formed. Its mole fraction increases until $1000 \mathrm{~K}$ and declines as temperature further increases. Another early product with a similar profile is 3 -furfural, however it is formed in only very small amounts. $\mathrm{CO}_{2}$ is detected as a minor product as soon as furfural begins to react. Its profile shows an interesting increase around $1000 \mathrm{~K}$, pointing to an additional formation pathway. Other major oxygenated products at higher temperatures are $\mathrm{CO}$ and furan. Both mole fraction profiles start to increase at 950 $\mathrm{K}$, which is about $50 \mathrm{~K}$ higher compared to the onset of furfural decomposition. Note that the furan mole fraction is less than $10 \%$ of that of CO. Vinylketene, which was identified by Grela et al. [10, 11] as a major component, has not been detected in this work. Ketenes are known to be difficult to analyze with the GC as they likely decompose prior to reaching the FID detector.

The major hydrocarbon products observed are methane, acetylene, propyne, propadiene and benzene. The propyne mole fraction is the highest and about double of the propadiene and acetylene mole fractions. All hydrocarbons are produced with a similar temperature shift as observed for CO. Smaller amounts of the aromatic products toluene, styrene, benzaldehyde and phenol are also detected. 

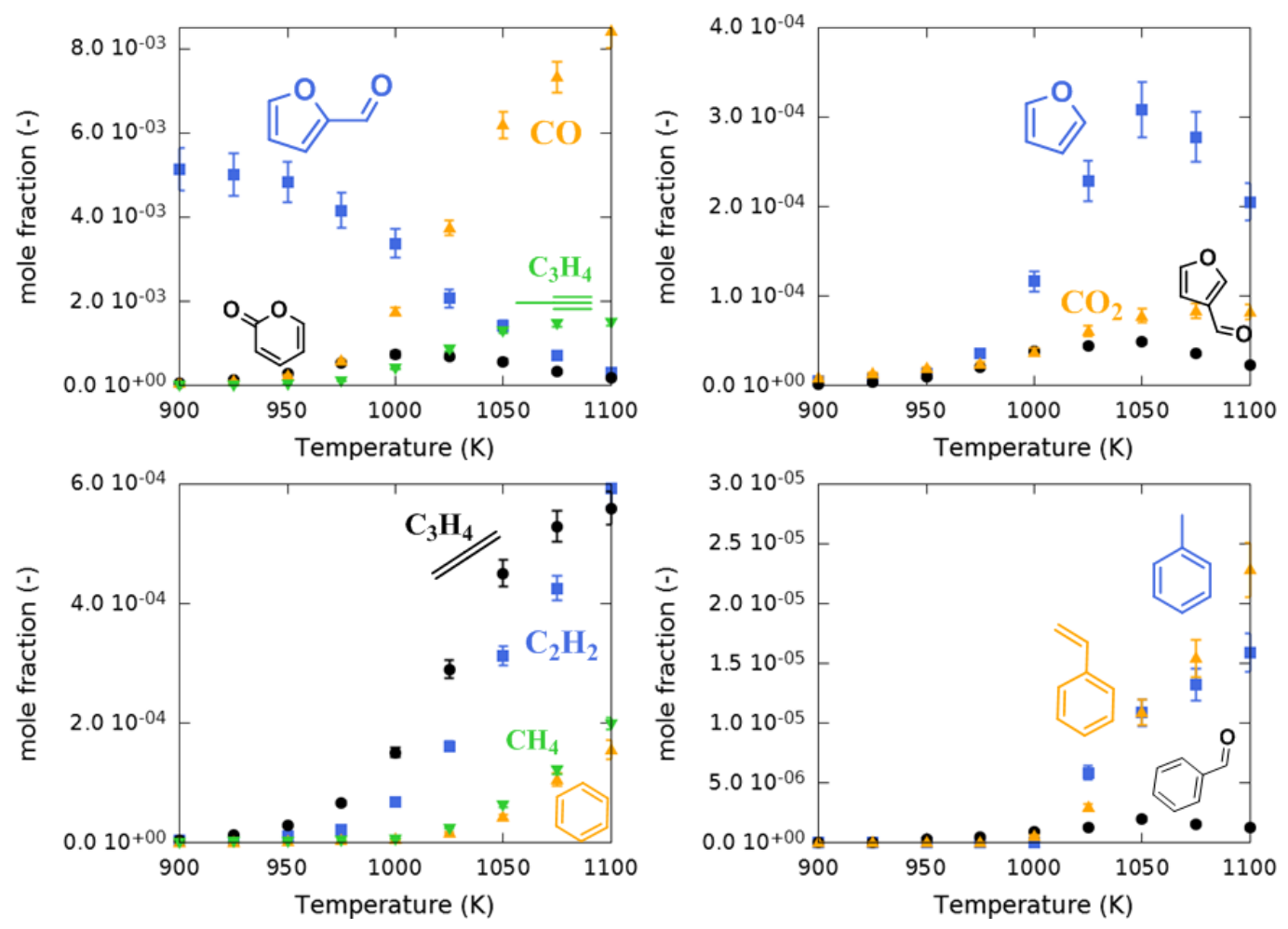

Figure 1. Main furfural pyrolysis product mole fractions. Experimental data (symbols), with experiments acquired in a jetstirred reactor $\left(\mathrm{x}_{\text {Furfural }}=0.005, \mathrm{p}=1.07\right.$ bar and $\left.\tau=2 \mathrm{~s}\right)$.

\subsection{Extended Potential Energy Surface}

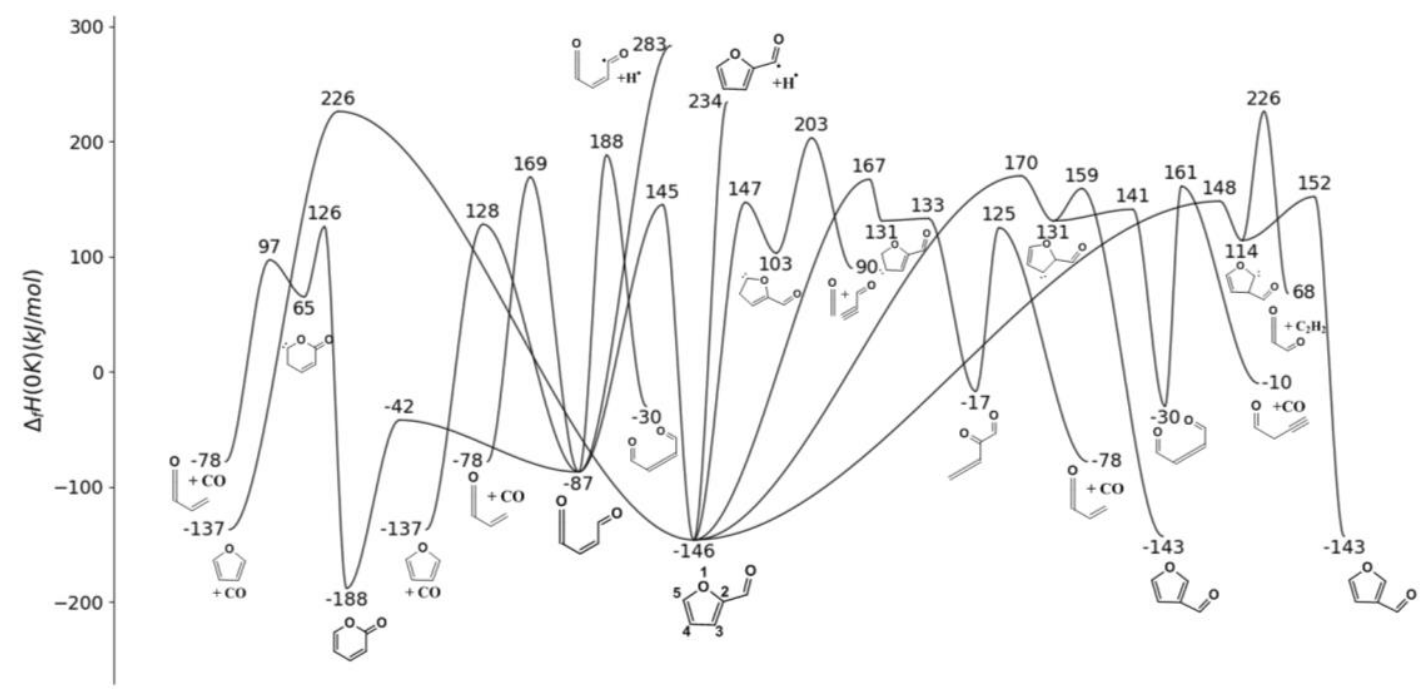

Figure 2. Selected part of the potential energy surface of furfural. Values are $\Delta_{\mathrm{f}} \mathrm{H}(0 \mathrm{~K})$ calculated at the CBS-QB3 level of theory in $\mathrm{kJ} / \mathrm{mol}$. 
The potential energy surface related to furfural decomposition has been constructed as part of this work and is shown in Figure 2. The pathways proposed by Vasiliou et al. [12] are confirmed, but numerous additional pathways are added to the $\mathrm{C}_{5} \mathrm{H}_{4} \mathrm{O}_{2}$ potential energy surface. New channels include (i) some selected homolytic $\mathrm{C}-\mathrm{H}$ bond scissions, (ii) carbenic channels starting from furfural with an isomerization pathway to 3-furaldehyde, (iii) the lowest energy carbenic pathway of $\alpha$-pyrone with the formation of $\mathrm{CO}$ and vinylketene and (iv) a pericyclic $\mathrm{CO}$ elimination from formylvinylketene to $\mathrm{CO}$ and vinylketene. The relevance of these new pathways will be discussed below.

\section{Discussion}

The product mole fraction profiles observed in the jet-stirred reactor experiments combined with the results from electronic structure calculations should provide insight in the thermal decomposition chemistry of furfural. The main products - $\mathrm{CO}$, propyne, propadiene, acetylene, and furan - are expected based on the previous studies. $\alpha$-pyrone is identified experimentally for the first time and it is a major product at lower temperatures. On the other hand, vinylketene could not be detected. Methane and small amounts of aromatic species are also produced at the selected experimental conditions, mainly at higher temperatures $(>1000 \mathrm{~K})$.

Below, the various channels that contribute to the thermal decomposition of furfural as proposed in literature are discussed. New pathways, which are indicated on the $\mathrm{C}_{5} \mathrm{H}_{4} \mathrm{O}_{2}$ potential energy surface, but also possible channels through bimolecular chemistry are proposed.

\section{Direct CO elimination}

The extensive product spectrum and the shifted furan and $\mathrm{CO}$ mole fraction profiles rule out the simplest furfural mechanism, which consists of the direct conversion of furfural to furan and CO via a 1,2 hydrogen atom shift. The barrier for this reaction is $372 \mathrm{~kJ} / \mathrm{mol}$ which is almost the same energy as needed for breaking the $\mathrm{C}-\mathrm{H}$ bond in the furfural carbonyl group $(380 \mathrm{~kJ} / \mathrm{mol})$. Given that the transition state for this reaction is tight, this channel will likely be unimportant at all conditions. The 
same conclusion was already made by Grela et al. [10,11] and Vasiliou et al. [12] and highlights the special nature of aromatic aldehydes.

\section{The $\alpha$-pyrone mechanism}

The observation of large yields of $\alpha$-pyrone at the onset of the furfural decomposition strongly supports the main pathway proposed by Vasiliou et al. [12] Since their experimental data mainly consists of mass spectra obtained with low ionization energy, hence suppressed fragmentation, they were not able to distinguish between different isomers and $\alpha$-pyrone was not identified as a product species. The current study provides a clear experimental evidence for this pathway as $\alpha$-pyrone is identified based on the expected retention time on the GC column and by its known mass spectrum. As can be seen in Figure 2, $\alpha$-pyrone is formed though furfural isomerization to formylvinylketene via a $191 \mathrm{~kJ} / \mathrm{mol}$ barrier. Formylvinylketene immediately forms $\alpha$-pyrone through a pericyclic ring closure reaction with a low barrier. Figure 2 also shows that $\alpha$-pyrone is $42 \mathrm{~kJ} / \mathrm{mol}$ lower in energy at $0 \mathrm{~K}$ (a somewhat surprising result because of the aromaticity of furfural), which explains why $\alpha$-pyrone is formed in high yields and why the furan and $\mathrm{CO}$ formation from formylvinylketene is suppressed even though the barrier for this reaction is $17 \mathrm{~kJ} / \mathrm{mol}$ lower than that for the initial formylvinylketene formation from furfural. The barrier for furan and CO formation from $\alpha$-pyrone is $314 \mathrm{~kJ} / \mathrm{mol}, 23 \mathrm{~kJ} / \mathrm{mol}$ higher than the initial barrier for $\alpha$-pyrone formation. Qualitatively these PES features thus not only explain the large amounts of $\alpha$-pyrone seen experimentally but also the shift in temperature of the occurrence of furan and $\mathrm{CO}$.

\section{Vinylketene formation}

The $\alpha$-pyrone mechanism discussed above clearly contradicts the experimental observations and interpretations by Grela et al. $[10,11]$. The known instability of ketenes might explain why no ketenes were measured with this experimental set-up. If vinylketene would be formed as an initial product then CO should be formed as a by-product. The experiments clearly show that $\mathrm{CO}$ formation starts at higher 
temperatures than $\alpha$-pyrone formation, hence vinylketene cannot be the initial product. Another argument that the assignment of vinylketene is doubtful relates to the problems discussed by Vasiliou et al. [12], i.e. the overlap of the IR bands of vinylketene with those of $\mathrm{CO}$ and furfural. Despite this experimental evidence against the formation of large amounts of vinylketene as an initial product, attempts were made to identify possible low-energy pathways to vinylketene on the PES. Three of those are depicted in Figure 2. The first pathway starts from formylvinylketene. Through a concerted $\mathrm{CO}$ elimination reaction, $\mathrm{CO}$ and vinylketene are formed. The barrier for this reaction is $256 \mathrm{~kJ} / \mathrm{mol}$. The second pathway starts from $\alpha$-pyrone. Formation of the $\alpha$-pyrone carbene with the carbenic carbon next to the lactone oxygen proceeds through a barrier of $314 \mathrm{~kJ} / \mathrm{mol}$, which is similar to the total barrier for furan and $\mathrm{CO}$ formation as discussed above. The $\alpha$-pyrone carbene eliminates $\mathrm{CO}$ to form vinylketene through a $32 \mathrm{~kJ} / \mathrm{mol}$ barrier reaction. The third vinylketene pathway with rather low total energy begins with the formation of furfural-3-carbene though a barrier of $313 \mathrm{~kJ} / \mathrm{mol}$. It rearranges to 2-keto,3,4-pentadienal which subsequently eliminates $\mathrm{CO}$ to form vinylketene. Even though these pathways are low enough in energy to have some importance, they do not provide evidence that vinylketene can be formed as important initial product.

\section{The role of carbene pathways}

Based on the $\alpha$-pyrone pathway, one would expect to detect the following products: $\alpha$-pyrone, furan, $\mathrm{CO}$ and pyrolysis products of furan (ketene, acetylene, propyne and $\mathrm{CO}$ ). Additional products that have been identified indicate that additional reactions take place. An obvious reaction family to consider is the one with carbene reactions similar to those studied by Sendt et al. [15] for the thermal decomposition of furan. Note that carbene chemistry has also been suggested to play a role in other substituted furans such as methyl and dimethyl furan [22-25]. Therefore electronic structure calculations are performed to investigate possible pathways involving carbene intermediates. Only the lowest energy pathways found are included in Figure 2. Carbenes can be formed by the shift of a hydrogen atom or by the shift of a carbonyl group. The HCO-shift has a barrier of $294 \mathrm{~kJ} / \mathrm{mol}$, only 3 
$\mathrm{kJ} / \mathrm{mol}$ higher compared to the furfural ring-opening isomerization to $\alpha$-pyrone. Through a subsequent hydrogen atom shift, with a transition state that has a $4 \mathrm{~kJ} / \mathrm{mol}$ higher energy, 3 -furaldehyde is formed. Because of the low difference in barrier, both pathways are energetically accessible, but the ringopening isomerization is expected to be dominant for entropic reasons. This is evidenced by the low amount of 3-furaldehyde detected experimentally, compared to the amount of $\alpha$-pyrone. Note that subsequent reactions of 3 -furaldehyde are omitted in Figure 2 for clarity.

1,2-hydrogen atom shift reactions in furfural lead to three carbene species, furfural-3-carbene, furfural4-carbene and furfural-5-carbene, with the carbenic carbon atom at position 3, 4 or 5 (see the numbering in Figure 2). Furfural-5-carbene differs from the two other carbenes as the carbenic site is located next to the oxygen atom in the ring structure. This difference is reflected in the barrier for the carbene formation, which is only $293 \mathrm{~kJ} / \mathrm{mol}$ for the 5 -carbene but $316 \mathrm{~kJ} / \mathrm{mol}$ and $313 \mathrm{~kJ} / \mathrm{mol}$ for furfural-3-carbene and furfural-4-carbene, respectively.

All three barriers are high compared to those reported by Sendt et al. [15] for the analogous carbene formation pathways in furan, calculated with CASPT2 and G2(MP2) methods. For the furan carbene with the carbenic site next to the ring-oxygen, the barriers are $280 \mathrm{~kJ} / \mathrm{mol}$ (CASPT2) and $270 \mathrm{~kJ} / \mathrm{mol}$ (G2MP2), hence 13 or $23 \mathrm{~kJ} / \mathrm{mol}$ lower respectively than for the similar furfural carbene. An even larger difference of almost $30 \mathrm{~kJ} / \mathrm{mol}$ is observed for the other carbenes. CBS-QB3 calculations for the decomposition channels of furan performed as part of the current study confirm these differences. The lower barriers for furan are also supported by Liu et al. [26] and by similar values found for dimethyl furan by Simmie et al. [24]. This suggests that the carbonyl group in furfural significantly destabilizes the 1,2-hydrogen atom shifts for all the positions in furfural. Given the similarity of barrier heights for the lowest energy carbene pathway and the ring-opening step forming $\alpha$-pyrone, it seems that this destabilization causes the $\alpha$-pyrone pathway to be dominant. If the barrier for the formation of carbenes would be similar to those found in other studies of (substituted) furan, these pathways would be the dominant ones. 
Besides the formation of 3-furaldehyde, furfural carbenes serve as intermediates in the formation of open-chain products, which can decompose by the molecular elimination of $\mathrm{CO}$. CO elimination generally occurs by a 1,2-hydrogen atom shift, with a high barrier, or through a retro-ene like reaction with a lower barrier. An example of these reaction types is given in Figure 3. The CO elimination reactions with the highest barrier are not shown on the potential energy surface in Figure 2.

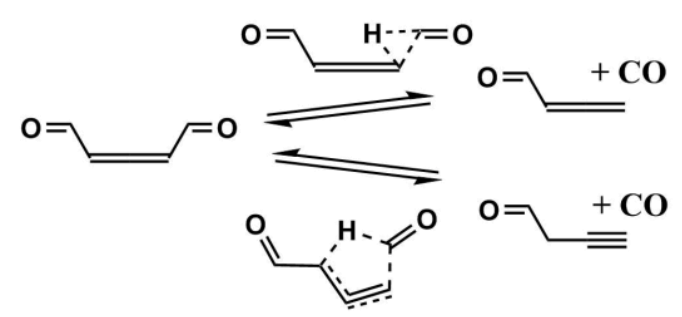

Figure 3. Example of a molecular CO elimination reaction. One channel has a high barrier with a 1,2-hydrogen atom shift (upper reaction) and one channel has a lower barrier with a retro-ene-like 1,4-hydrogen atom shift (lower reaction)

\section{The role of Diels Alder reactions}

Diels Alder reactions are known to have a low barrier and may play an important role in systems that are low in radical concentrations, such as this furfural study. With $\alpha$-pyrone as the diene component a particular interesting set of Diels Alder reactions is possible, because the formed Diels Alder adduct can immediately undergo a reverse Diels Alder reaction releasing $\mathrm{CO}_{2}$. With acetylene and propyne as 'ene' reactants the aromatic products benzene and toluene are formed. Both products are detected in the current study. A schematic representation of this reaction is given in Figure 4.

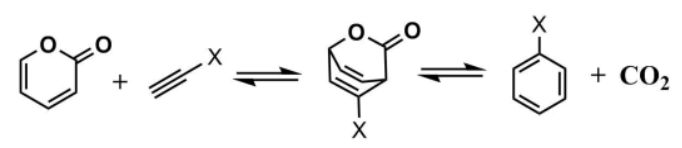

Figure 4. Formation of aromatic products through Diels Alder reactions of $\alpha$-pyrone with (substituted) acetylene.

In the experiments, small amounts of styrene and benzaldehyde are detected as well. For benzaldehyde production the 'ene' component necessary is formylacetylene, which can be formed via the carbene pathway of furfural-5-carbene (see Figure 2). A similar reaction to form styrene would require 
vinylacetylene as 'ene' component. Considering only molecular chemistry it is difficult to identify pathways for vinylacetylene formation and indeed, it has not been detected in large amounts experimentally. If radicals would make a contribution to the formed product species, as discussed next, small amount of vinylacetylene could be formed.

\section{Radical chemistry}

Grela et al. [10, 11] and Vasiliou et al. [12] did not observe radicals in their experiments. Both experiments were conducted at low pressures, high dilutions and in tubular reactors. The experimental dataset in this work is obtained in a jet-stirred reactor, a set-up which favors radical chemistry. Therefor the involvement of radical chemistry, in particular at higher temperatures, cannot be excluded. Methane, which is clearly observed experimentally, is difficult to form by any reaction type other than hydrogen abstraction reactions. For radicals to play a role, a radical pool has to be formed first. Weak $\mathrm{C}-\mathrm{H}$ bonds are found in the carbonyl group of furfural and formylvinylketene. The bond dissociation energies are $380 \mathrm{~kJ} / \mathrm{mol}$ and $369 \mathrm{~kJ} / \mathrm{mol}$ respectively, as can be seen in Figure 2. These values are significantly higher than the barriers for the ring-opening isomerization of furfural. Therefore radicals likely do not play a notable role at low temperatures but only at higher temperatures. Methane starts to be formed around $1000 \mathrm{~K}$. At the same temperature a sudden increase in the benzene mole fraction and $\mathrm{CO}_{2}$ is observed experimentally. Most probably, radical chemistry influences conversion and species mole fractions starting from $1000 \mathrm{~K}$ and a kinetic model for furfural pyrolysis should contain radical chemistry as well as the reaction classes discussed in previous sections.

\section{Conclusions}

The chemistry of the thermal decomposition of furfural is studied experimentally and by means of theoretical calculations. Experiments are performed in a jet-stirred reactor at atmospheric pressure and temperatures between $900 \mathrm{~K}$ and $1100 \mathrm{~K}$ using online gas chromatography for product analysis. The experimental dataset confirms the proposed mechanism by Vasiliou et al. that furfural decomposes mainly though a ring-opening isomerization with the formation of formylvinylketene as intermediate 
and $\alpha$-pyrone as a stable product. On the other hand, no experimental evidence was found to support the observation of Grela et al. that vinylketene is formed as an initial product. The mole fractions of major products like $\mathrm{CO}$, furan, acetylene, propyne and propadiene can be explained by the $\alpha$-pyrone mechanism followed by furan decomposition. Mole fraction profiles of other product species suggest that more chemistry occurs than expected.

Theoretical calculations at the CBS-QB3 level of theory are performed and the furfural potential energy surface is extended with new pathways. Channels through carbene intermediates are found to contribute slightly to furfural conversion and species mole fractions. An isomer, 3-furaldehyde, can be formed through a carbene pathway that is initiated by a carbonyl group shift. Pericyclic reactions make molecular CO elimination possible. Diels Alder reactions are found to contribute to the formation of aromatics, like benzene, toluene, styrene and benzaldehyde. Also the formation of radicals plays an important role at higher temperatures, most probably $>1000 \mathrm{~K}$.

The new experimental measurements and theoretical data will be useful to construct a detailed kinetic model for this interesting molecule.

\section{Acknowledgements}

This work was carried out using the STEVIN Supercomputer Infrastructure at Ghent University, funded by Ghent University, the Flemish Supercomputer Center (VSC), the Hercules Foundation and the Flemish Government - department EWI. The authors would like to acknowledge the financial support from the SBO proposals "Bioleum" and "Arboref" supported by the Institute for promotion of Innovation through Science and Technology in Flanders (IWT).

\section{References}

[1] K.M. Van Geem, I. Amghizar, F. Vermeire, R. De Bruycker, Production of Bio-Oil, in: M.R. Riazi (Ed.) Biofuels Production and Processing Technology, CRC Press 2017, pp. 199-246.

[2] J.Q. Bond, D.M. Alonso, D. Wang, R.M. West, J.A. Dumesic, Science, 327 (2010) 1110-1114.

[3] C.E. Greenhalf, D.J. Nowakowski, A.B. Harms, J.O. Titiloye, A.V. Bridgwater, Fuel, 108 (2013) 216-230. 
[4] L. Negahdar, A. Gonzalez-Quiroga, D. Otyuskaya, H.E. Toraman, L. Liu, J.T.B.H. Jastrzebski, K.M. Van Geem, G.B. Marin, J.W. Thybaut, B.M. Weckhuysen, ACS Sustainable Chemistry \& Engineering, 4 (2016) 4974-4985.

[5] A. Corma, O. de la Torre, M. Renz, N. Villandier, Angewandte Chemie International Edition, 50 (2011) 2375-2378.

[6] P.R. Patwardhan, R.C. Brown, B.H. Shanks, ChemSusChem, 4 (2011) 636-643.

[7] J.-P. Lange, E. van der Heide, J. van Buijtenen, R. Price, ChemSusChem, 5 (2012) 150-166.

[8] J.J. Bozell, G.R. Petersen, Green Chemistry, 12 (2010) 539-554.

[9] C.D. Hurd, A.R. Goldsby, E.N. Osborne, Journal of the American Chemical Society, 54 (1932) 2532-2536.

[10] M.A. Grela, A.J. Colussi, J. Phys. Chem., 90 (1986) 434-437.

[11] M.A. Grela, A.J. Colussi, An. Asoc. Quim. Argent., 75 (1987) 111-115.

[12] A.K. Vasiliou, J.H. Kim, T.K. Ormond, K.M. Piech, K.N. Urness, A.M. Scheer, D.J.

Robichaud, C. Mukarakate, M.R. Nimlos, J.W. Daily, Q. Guan, H.-H. Carstensen, G.B. Ellison, The Journal of Chemical Physics, 139 (2013) 104310.

[13] S. Wu, H. Yang, J. Hu, D. Shen, H. Zhang, R. Xiao, Journal of Analytical and Applied Pyrolysis, 120 (2016) 252-257.

[14] M.A. Grela, V.T. Amorebieta, A.J. Colussi, The Journal of Physical Chemistry, 89 (1985) 3841.

[15] K. Sendt, G.B. Bacskay, J.C. Mackie, The Journal of Physical Chemistry A, 104 (2000) 18611875.

[16] O. Herbinet, F. Battin-Leclerc, Int. J. Chem. Kinet., 46 (2014) 619-639.

[17] J.A. Montgomery, M.J. Frisch, J.W. Ochterski, G.A. Petersson, J. Chem. Phys., 110 (1999) 2822-2827.

[18] M.J. Frisch, G. W. Trucks, H. B. Schlegel, G. E. Scuseria, M. A. Robb, J. R. Cheeseman, G. Scalmani, V. Barone, B. Mennucci, G. A. Petersson, H. Nakatsuji, M. Caricato, X. Li, H. P. Hratchian, A. F. Izmaylov, J. Bloino, G. Zheng, J. L. Sonnenberg, M. Hada, M. Ehara, K. Toyota, R. Fukuda, J. Hasegawa, M. Ishida, T. Nakajima, Y. Honda, O. Kitao, H. Nakai, T. Vreven, J. A. Montgomery, Jr., J. E. Peralta, F. Ogliaro, M. Bearpark, J. J. Heyd, E. Brothers, K. N. Kudin, V. N. Staroverov, R. Kobayashi, J. Normand, K. Raghavachari, A. Rendell, J. C. Burant, S. S. Iyengar, J. Tomasi, M. Cossi, N. Rega, J. M. Millam, M. Klene, J. E. Knox, J. B. Cross, V. Bakken, C. Adamo, J. Jaramillo, R. Gomperts, R. E. Stratmann, O. Yazyev, A. J. Austin, R. Cammi, C. Pomelli, J. W. Ochterski, R. L. Martin, K. Morokuma, V. G. Zakrzewski, G. A. Voth, P. Salvador, J. J. 
Dannenberg, S. Dapprich, A. D. Daniels, Ö. Farkas, J. B. Foresman, J. V. Ortiz, J. Cioslowski, and D. J. Fox, in, Gaussian, Inc., Wallingford CT, 2009.

[19] A.L.L. East, L. Radom, J. Chem. Phys., 106 (1997) 6655-6674.

[20] L.A. Curtiss, K. Raghavachari, P.C. Redfern, J.A. Pople, J. Chem. Phys., 106 (1997) 1063-1079.

[21] G.A. Petersson, D.K. Malick, W.G. Wilson, J.W. Ochterski, J.A. Montgomery, M.J. Frisch, J. Chem. Phys., 109 (1998) 10570-10579.

[22] B. Sirjean, R. Fournet, P.-A. Glaude, F. Battin-Leclerc, W. Wang, M.A. Oehlschlaeger, The Journal of Physical Chemistry A, 117 (2013) 1371-1392.

[23] M. Verdicchio, B. Sirjean, L.S. Tran, P.-A. Glaude, F. Battin-Leclerc, Proceedings of the Combustion Institute, 35 (2015) 533-541.

[24] J.M. Simmie, W.K. Metcalfe, The Journal of Physical Chemistry A, 115 (2011) 8877-8888.

[25] K.P. Somers, J.M. Simmie, W.K. Metcalfe, H.J. Curran, Physical Chemistry Chemical Physics, 16 (2014) 5349-5367.

[26] R. Liu, X. Zhou, L. Zhai, Journal of Computational Chemistry, 19 (1998) 240-249. 


\section{List of Figure captions}

Figure 1. Main furfural pyrolysis product mole fractions. Experimental data (symbols), with experiments acquired in a jet-stirred reactor $\left(\mathrm{x}_{\text {Furfural }}=0.005, \mathrm{p}=1.07\right.$ bar and $\left.\tau=2 \mathrm{~s}\right)$. 8

Figure 2. Selected part of the potential energy surface of furfural. Values are $\Delta_{\mathrm{f}} \mathrm{H}(0 \mathrm{~K})$ calculated at the CBS-QB3 level of theory in $\mathrm{kJ} / \mathrm{mol}$ .8

Figure 3. Example of a molecular $\mathrm{CO}$ elimination reaction. One channel has a high barrier with a 1,2hydrogen atom shift (upper reaction) and one channel has a lower barrier with a retro-ene-like 1,4-

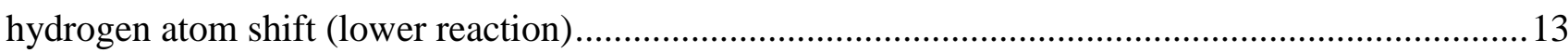

Figure 4. Formation of aromatic products through Diels Alder reactions of $\alpha$-pyrone with (substituted) acetylene.

\section{List of supporting information}

SupportingInfo_ExperimentalData.xlsx 